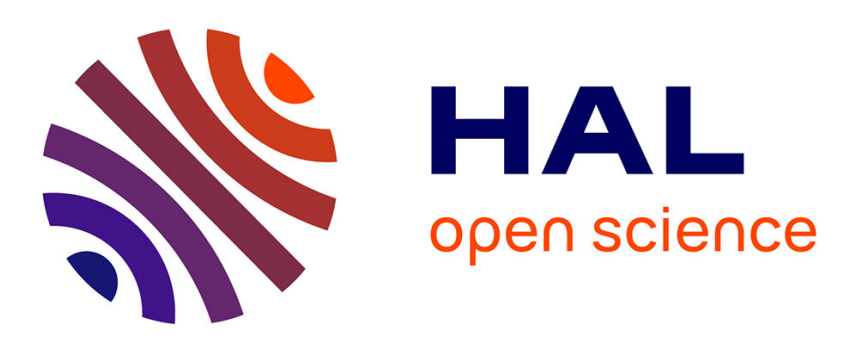

\title{
Using of the concepts of roles and context in a project management / PLM solution: the real case study of Lascom
}

Mylène Baczkowski, Vincent Robin, Bertrand Rose

\section{To cite this version:}

Mylène Baczkowski, Vincent Robin, Bertrand Rose. Using of the concepts of roles and context in a project management / PLM solution: the real case study of Lascom. ASME2012 11th Biennial Conference on Engineering Systems Design and Analysis, Jul 2012, Nantes, France. pp.443-452, 10.1115/ESDA2012-82784 . hal-00990077

\section{HAL Id: hal-00990077 https://hal.science/hal-00990077}

Submitted on 24 Apr 2019

HAL is a multi-disciplinary open access archive for the deposit and dissemination of scientific research documents, whether they are published or not. The documents may come from teaching and research institutions in France or abroad, or from public or private research centers.
L'archive ouverte pluridisciplinaire HAL, est destinée au dépôt et à la diffusion de documents scientifiques de niveau recherche, publiés ou non, émanant des établissements d'enseignement et de recherche français ou étrangers, des laboratoires publics ou privés. 
ESDA2012-82784

\section{USING OF THE CONCEPTS OF ROLES AND CONTEXT IN A PROJECT MANAGEMENT/PLM SOLUTION: THE REAL CASE STUDY OF LASCOM}

\author{
Mylène BACZKOWSKI \\ LASCOM \\ 4 Route de Gisy \\ 91570 Bièvres, France
}

\author{
Vincent ROBIN \\ IMS Laboratory, \\ University of Bordeaux \\ 351 Cours de la Libération \\ 33405 Talence, France
}

\author{
Bertrand ROSE \\ LGeCo Laboratory, \\ INSA de Strasbourg \\ University of Strasbourg \\ 24 Bld de la Victoire \\ 67084 Strasbourg, France
}

\begin{abstract}
The software tools for PLM and project management are often built around several classical concepts: Processes, Activities, Phases, Artefacts, Workflows, Resources and Relationships. This approach does not really consider the team concept and the particular dynamics of the project management. This leads to a paradox with PLM and project management software tools. They tend to reduce risk and improve performance by structuring, streamlining, automating and scheduling projects without considering projects are not wellstructured and have their own dynamic. The negation of project management mode increases the risks of project failures, adds stress to team members and requires the addition of complex mechanisms of collaboration and delegation. PLM Software sometimes becomes a limitation for project management. Our partner, LASCOM, a French PLM software developer, decided to make evolve its solutions to provide customers more efficient PLM solutions. LASCOM initiated a reflection around new concepts for enrich its existing models and tools since few years. The company particularly has an interest on the practical use of the concepts of roles and contexts. This paper deals with the addition of these concepts in the models used by LASCOM. This addition is intended to partially solve the problems posed by the generalization of work by project in organizations.
\end{abstract}

\section{INTRODUCTION}

The launch of a project is a response to a production effort applied to an organization. By its nature, it has a high degree of uncertainty and allows a high reactivity. The generalization of project organization within companies has the effect of changing the criteria for evaluating this type of management. Yet it is necessary to find a compromise between the need for the organization to master its processes and the project dynamics. For this, the approach presented here proposes to focus on the concepts of context and associated roles. The concept of context is considered as one or a set of specific situations in the course of a project. The concept of role, independent of the concept of actor, is described as a cluster of behaviors and goal-oriented context-specific. This approach has the effect to permit to structure process for managing the organization and a more dynamic project management.

While focusing on design project, the cornerstone of the product development process is the performance. After having introduced models to run an efficient product development performance evaluation, the second section part of this paper outlines the similarities between project management and operational management of an organization. We analyze the opportunity to use organization management models for managing product development projects. The third part presents and analyses the software project management solution of our partner LASCOM to make appear its strong points and its weak spots. The fourth part therefore proposes models to help to soften the effects of changing management practices on projects by introducing the notion of roles and context. 


\section{DESIGN PROJECT MANAGEMENT CONCEPTS}

The complexity of engineering design processes continuously increases and objectives of cost, delay and quality are more and more restrictive. From now on, they have to integrate a great number of expertises based on collaboration between the different actors involved. In such a context, design management consists in the definition and the organization of the system where the design transformation will take place, according to the needs for collaboration and design objectives. So, co-ordination and control of design are part of a global approach for the development of new products that implies the need to identify the different situations occurring during the design process and the adequate resources to satisfy design objectives. The design situations are described by identifying components of the design activity and their relationships $[1,2]$. As a consequence, design project management and control of the design process are defined as the understanding and the evaluation of these existing design situations to take decisions. These decisions will modify and improve the future process, according to design objectives given by customer specifications or the company strategy. In a nutshell, management of design projects is a decision-making problem to support designers in their activities and achieve an objective in a specific design context [3]. This context has an influence on the project and refers to the environment of the enterprise (society, market, subcontractors, etc) and to its organization [4]. Influences of the context affect each entity of the organization. Sudarsan et al. [5] proposed a high level view of these influences in their adaptation of the epicycle diagram from [6] (Figure 1). It explains the epicycle nature of PLM and characterizes the information flow pattern in any product lifecycle.

The PLM epicycle current view emphasis that many kinds of information have to be considered and managed to ensure a coherent multi-level project management adapted to each decision-maker at each decision-level. In such a context, PLM support needs to connect the product design and analysis processes to the production and supply chain processes, including: product data management (PDM), component supplier management (CSM), enterprise resource planning (ERP), manufacturing execution systems (MES), customer relationship management (CRM), supply and planning management (SPM), and others that will undoubtedly follow [7]. Objective is to provide to each project manager a set of information representative of the real state of design situation. All the information has to be synchronized for each project in the organization to ensure coherence of the project management. Information has also to be continuously defined and characterized to permit an efficient decision-making during the project progress. It is possible if all information flows, for each project are traced, analyzed and exploited to follow-up the design project. Approach that is frequently adopted is to decompose the strategies and objectives through a hierarchical structured organization [1].

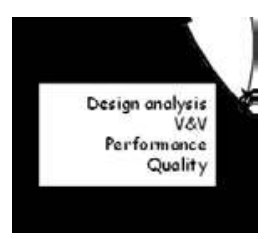

Figure 1. PLM epicycle current view [5]

For several years, the Balanced Scorecard (BSC) is widely applied in organizations [8]. Using the BSC as a tool for measuring and controlling the product development process has already been highlighted [9]. However the nature of a product development project is not that of an organization, the diversity of factors that determine the performance and success of the development process must also be considered. More specifically, models of performance assessment in design exist. The take into account indicators as: Efficiency, Effectiveness, Collaboration, Management Skill and Innovation. ENAPS Performance Measurement Cube [10], Performance Pyramid [11], Pawar and Driva's framework for product development performance metrics [12, 13] or the Integrated Performance Measurement Framework [14] are some of these models. They permit the decomposition of strategies and objectives through a hierarchical structured organization and describe interactions that exist between each operational activities of the design process. But the two most significant models in the evaluation of the performance management design are GRAI R\&D [15, 16, 17] and the O'Donnell and Duffy methodology [18] for design performance modeling and analysis. These generic models of design activity performance insist on the necessity to identify components of an activity and their relationships [17, 19]. Nevertheless, they don't clearly explain nature of these interactions and as a consequence, reduce efficiency of the design management. In fact, these models often focus on an organizational point of view without project management perspective instead of focusing on the uniqueness of activities as in Project Management theory. Interest for LASCOM is to identify the similarities and differences between project management and operational management of an organization to make evolve its software solutions. As we can nevertheless raise the question of the compatibility between the concepts of project and organization in term of product development performance, following section outlines. 


\section{PROJECT VS ORGANIZATION?}

In a manufacturing company, the product development (PD) always requires efforts to the business organization. The success and the performances of a PD project can be viewed in different ways [20]. The two main categories of perspectives on the success of a PD project come from the project management and the organization.

From the project management point of view, the successful completion of a project is linked to the capabilities of project control [21,22]. Controlling is a combination of three elements: monitoring, deciding and taking correctives actions. The control can be view as comparing actual performance with planned performance, analyzing variances and exceptions, assessing trends to effect process/activities improvements, evaluating possible alternatives, and recommending appropriate correctives actions as needed [21, 22]. This control over the project is dependent on the performance evaluation of the project process. In the context of PD projects, the key process is the design process. Its evaluation can be separated into two strongly linked categories: the performance of the design activity and the performance of the design management activity [18,23].

From an organizational point of view, the success of a project is linked to the iron triangle: cost, time, quality [24]. The performance evaluation focuses on quality of the processes and results especially with the financial results - the Return On Investment (ROI). To summarize, there are two categories of logic for performance assessment of a PD project. The organization is interested in the "income and outcome evaluation" while project management focuses on the ongoing evaluation of the project process.

The models used for performance evaluation in Product Development previously depicted emphasize on the fact that, even if they are mainly targeted towards the organizational point of view, they are nevertheless fully compatible with a project management point of view. They can also be, in some conditions, complementary. In this way they are fully embedded in the current trend that is to apply the criteria of the organizational management to the project management. As a consequence, risk management and excessive planning become therefore today mandatory. Indeed, structuring and streamlining become key issues of project management. This has the effect of turning the practices of project management into practices similar to those in the operational management of organization [24]. This trend is accentuated by the fact that the models for project management and organizational management are similar. These models are mostly seen through the processes involved. They use modeling concepts which are processes, activities, phases, artifacts, flows, resources and relationships $[25,26]$. It is clearly stated in the project management literature like in $[21,22]$. Authors encourage the PD project manager to use performance indicators derived from the iron triangle (cost, time, quality) associated with context-specific indicators linked with the development of a particular product.
This trend was first promoted by Wheelwright and Clark [27] while proposing a typology of projects based on the policy level of the project manager. This typology is presented with a continuum between a traditional organization and an organization with autonomous projects: "functional", "lightweight", "heavyweight", "autonomous". In the functional project, no individual has overall responsibility for the process, It is the department managers that ensure the allocation and coordination of the resources mobilized in the project. The organization type "lightweight" and "heavyweight" correspond to a matrix-type organization, the leaders of the "heavyweight" have more power than the leaders of the "lightweight" project type. In the "autonomous project," the working actors of the project are physically and institutionally out of the organization structures and are under the authority of project manager for the duration of their intervention. Each type of configuration is done for a particular context. Project work and organization work are not two opposite ways of thinking about the work. They are both complementary necessities. This is reflected in the way to manage teams. The differences between the administration and project organization are especially visible for product development projects.

A development product project behaves as a complex system whose completion is not linear. This fact distinguishes the project from the ongoing operations of an organization and allows the project to be more effective on a given time interval [28]. This system cannot be understood according to a single point of view. It is essential to have different views on the development project and its environment $[25,26]$. Because of their different nature, each component of this type of project can be seen following separate processes with different life cycles. In addition, a product development project is multidisciplinary. Each discipline involved brings a series of contributions to the development of the final product which are of two types: indirect and direct. Indirect ones come from disciplines whose processes are doing the support and project management: Organizational Management and Project Management. Direct contributions from disciplines whose processes are involved in shaping the final product: marketing, design and manufacturing [29]. These processes can be divided according to uncertainties and risks they create in an organization [30] and especially in a project [31]: The process standards are most strongly associated with the operation of own organization, routine process are mainly in the project management processes and non-routine activities are directly related to the design of a product.

This categorization (Figure 2) is not settled. It helps to understand that the central process of a project is the most uncertain processes. This is especially true for a process of product development. According to Simon [32], this uncertainty is mainly due to the fact that the product design process is characterized by an initial ill-defined state and some unknown solutions where only the most acceptable solution is selected. The transition between the state "undefined" and the appropriate condition is achieved by a succession of stages of 
representations. During these stages, a set of activities of reasoning and problem solving are implemented in nonstructured way or with adequate methodologies, depending on clarity of the problematic. However, the understanding of the human mechanisms for generating and evaluating solutions is still biased [33]. This explains why the models and methods of design science are nondeterministic and still implements by humans $[25,32]$.

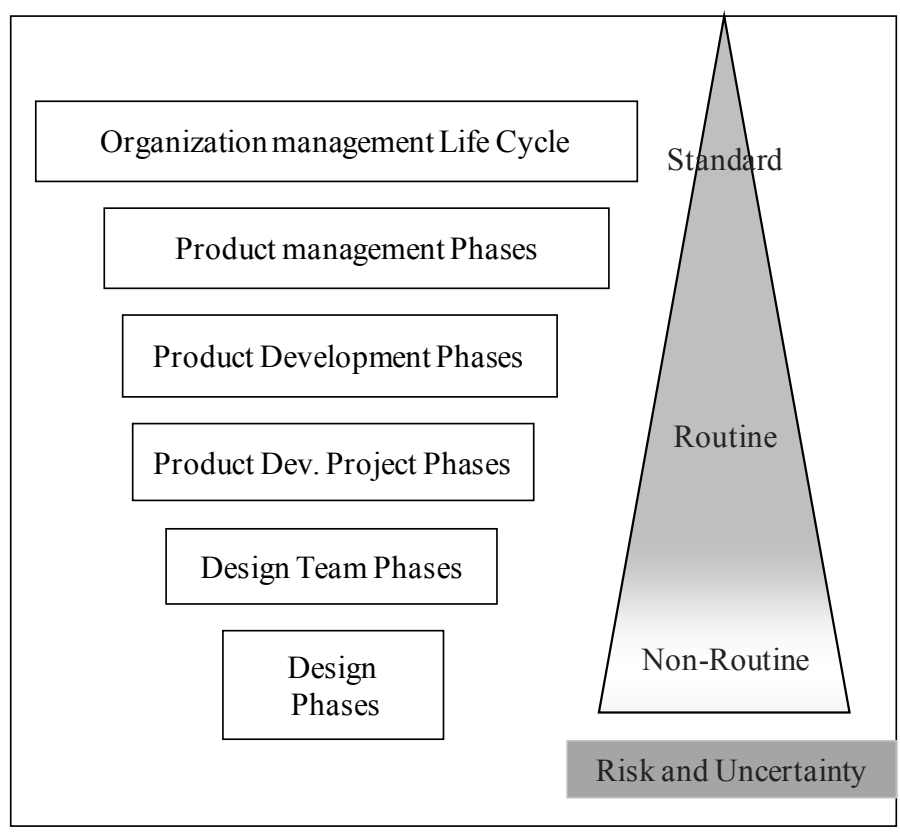

Figure 2. Project component versus Risk and Uncertainty

The goal of a product development project is to define a product but also to find optimal ways to achieve this definition. This implies, from the development project team, some choices throughout the design process. Each choice is the result of a series of decisions based on criteria specific to the project objectives. These choices are characterized by their scope, their time horizon and their level of risk. The evolution of the couple risk / uncertainty has implications for how to manage a project. De Meyer et al. [34] propose a characterization of uncertainty in a project. They fall into four categories. They also present ways to manage a project based on uncertainty. These categories are: complete uncertainty characterized by Chaos through Unforeseen Uncertainty, Foreseen Uncertainty and finally. A lack of uncertainty is characterized by simple variations. By their very different natures (Table1), the modes of risk management, planning and resources for the project are different from the ones in organization. On one hand, the project is closer to a characteristic of chaos, it requires decisions based on incremental learning, continual redefinitions, quick returns on its progress. On the other hand, the organization has more stable process and that each activity has a low potential for financial and temporal variations. In this case, planning can be comprehensive and takes into account variations in the type of activity.

\begin{tabular}{|c|c|}
\hline Project & Organization \\
\hline $\begin{array}{c}\text { Not repeatable / temporary / } \\
\text { fast }\end{array}$ & $\begin{array}{c}\text { Repetitive / permanent / } \\
\text { slow }\end{array}$ \\
\hline Irreversible decisions & Reversible decision \\
\hline Iterative process & Linear process \\
\hline $\begin{array}{c}\text { Strong influence of } \\
\text { exogenous variables }\end{array}$ & $\begin{array}{c}\text { Strong influence of } \\
\text { endogenous variables }\end{array}$ \\
\hline Major strategic issue & No major strategic issue \\
\hline Historical process & $\begin{array}{c}\text { stable process , manageable } \\
\text { with ahistorical Statistics }\end{array}$ \\
\hline Reactive and informal & Standardization and formal \\
\hline customer satisfaction \\
Oriented & process quality oriented \\
\hline Team management & Group management \\
\hline Negative Cash flow & Positive Cash flow \\
\hline
\end{tabular}

Table 1. Project Vs Organization from [24, 28, 30]

The management style has an impact on human resources and competences. The project team is a group of people whose main objective is the response to needs stated at the beginning of the project. For this, each member is required to contribute to the advancement of a process according to the tasks assigned. It is a set of participants where the majority of objectives, actions, accountabilities and results are shared [35, 36]. The team is characterized by the duality individual / group, where the individual is at the service group [37]. This involves collaborative and cooperative interactions, at particular moments during the project. The organizational management considers the group. This work group is a set of participants where leadership is centralized and where each individual, according to its own objectives, is accountable for its actions and results.

The generalization of project accelerates the shift patterns of organizational management to the projects. This transfer results in the use of criteria for performance evaluation processes own organization and implementation of inappropriate management of projects. The differences between these two modes of management are blurred in the models used for software project management. Our proposition is to make evolve some parts of these models and particularly LASCOM ones. We are not authorized to present the core product/process model of LASCOM PLM, it is naturally confidential. As a consequence, we just provide a global description of the structure of this PLM solution in the following section. Nevertheless, some part of the model will be analyzed in the last section of the paper.

\section{PROJECT MANAGEMENT SOFTWARE OF LASCOM}

The LASCOM PLM Solution for the project management improves the efficiency and visibility of key business processes through workflow software and easy-to-use web interfaces. Internal and external stakeholders can more effectively collaborate on key areas such as project score carding, new product/project development, change management, and crisis 
management. This increases time-to-market and greatly reduces the financial, legal, and brand image risks when inadvertent errors are made. The core of the software is the Product / Project Information Repository (PIR) Module, which is used to manage all product related data, documents, and event information and is the foundation upon which all other PLM Solution modules depend. Specifically, the PIR's role is to:

- Securely manage all project, product information and their inter-relationships;

- Structure views of the product or project information based on these inter-relationships;

- Enable information access through a sophisticated range of search \& reporting tools;

- Allow users to create, reuse, and modify the information based on security access rights;

- Facilitate analysis of the information using advanced features such as comparisons, gap analysis, where-used, and impact-analysis;

- Allow detailed auditing of all PIR activity.
This solution uses a link manager to represent the interactions between different objects of the data model. This capability is the basis of its proven configuration management component. One key element of any knowledge base is the ability to manage these objects and the documents in a wide variety of formats (Figure 3). Documents can consist of internal documents and templates, where versioning and properties are managed, as well as external documents where such information might not be available or applicable. In addition, documents can also be organized into virtual folders of related documents or related to an unlimited number of other documents. Any document can have an arbitrary number of descriptive fields and properties (for the purposes of system definition, management, and end-user searching. Many organizations choose to manage document security and access rights based on the value of a particular document field, version, status or other property. LASCOM PLM Information Repository includes a built-in document management system with standard functions. It therefore maintains the complete design intent of the data and can be used to trace why certain decisions were made.

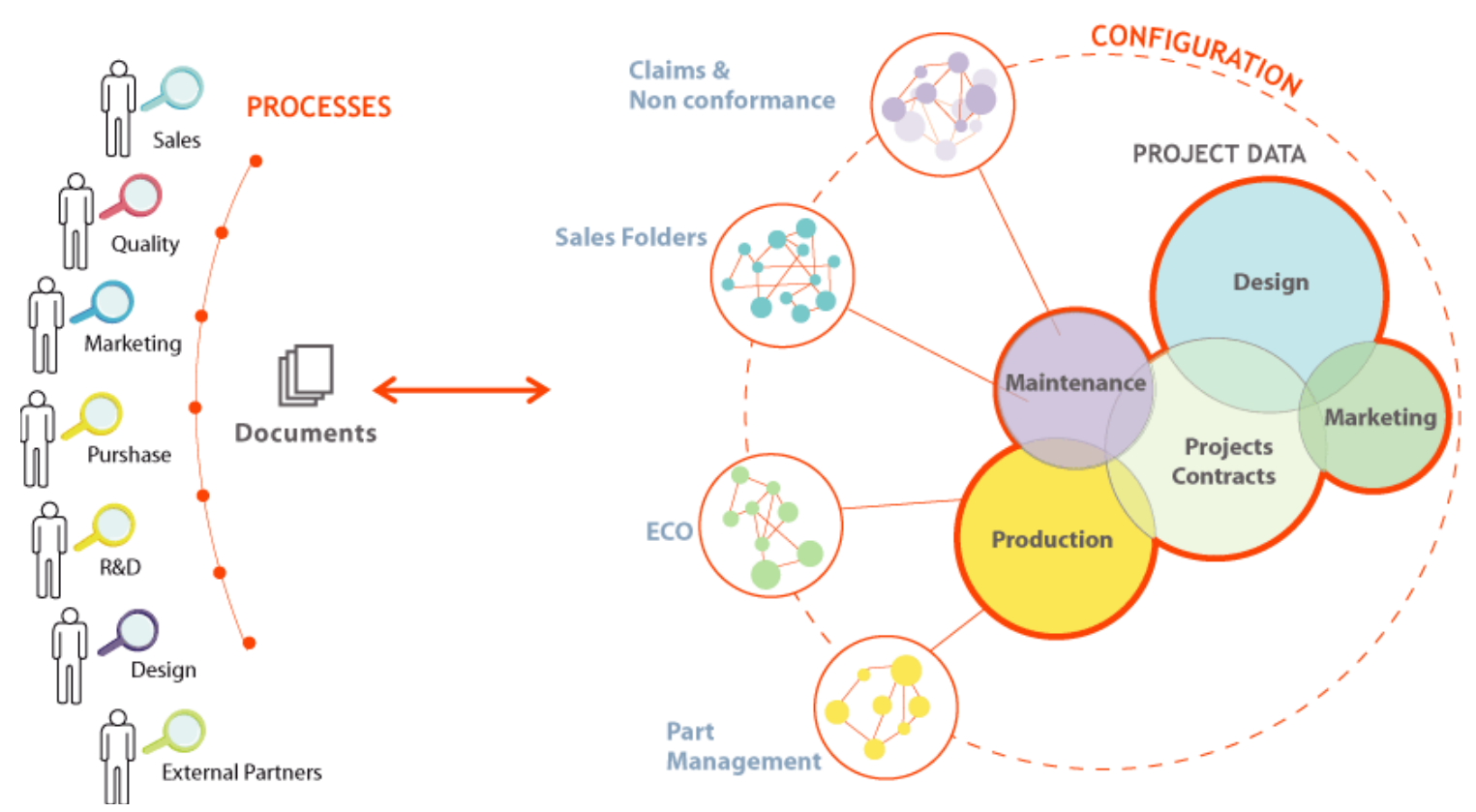

Figure 3. LASCOM PLM environment and the important place of documents

As many software tools for project management [38, 39, $40,41]$ LASCOM PLM is based on a process approach [42] that refers to the same 7 concepts from the literature in project management [21, 22, 25, 26, 43]: Processes, Activities, Phases, Artifacts, Workflows, Resources and Relationships. The trend of the software to amplify a change in practice towards managing operational organization is scattered in several places in different modules of the software. The most notable are the modules for planning, risk management and assessment of performance. Whatever the view, the planning modules are linked to representations by Gantt. Each resource is individually detailed and temporally represented linearly. Risk Management tools allow a qualitative or quantitative analysis of risk. They are strongly related to planning modules. The tools for performance analysis are link to the trilogy: time, cost, quality from business management. In LASCOM PLM, the team concept is clearly described as a set of functional actors or stakeholders. Their activities are described according to their position in a project. In this context, each actor represents the archetype of a class of individuals within a project. Each actor is qualified by a list of activities. This model comes from the organizational management. The models used do not really 
consider the team concept and do not take into account the particular dynamics of the project management. This leads to a paradox with software project management: On the one hand, project management solutions tend to want to reduce risk and improve performance by structuring, streamlining, automating and scheduling [44] and on the second hand, the project in the real world must be dynamic. The negation of project management mode increases the risks of project failure adds stress to team members and requires the addition of complex mechanisms of collaboration and delegation. Software project management becomes a limitation from a project $[45,46]$. This has an important impact on managing the project team. The results of this changes lead to limitations in project management such as: a lack of flexibility in term of competence management, individualization of tasks, low diversity profiles of potential players and finally reduced opportunities for operational implementation of the project. The following section presents our propositions to provide an answer to the limitations of project management solutions of LASCOM.

\section{MANAGING WITH ROLES AND CONTEXTS}

A simple solution could be envisaged to solve this paradox. It would be to incorporate a true management style of autonomous project. In this solution all the characteristics of a project would be met. However, this solution cannot be considered because it disconnects the project from the organization that supports it. Besides, this goes to the opposite of the operational paradigm requiring the identification and careful formalization of the link between human resource and industrial performance, through concepts like skills, competencies or know-how [47]. In addition, projects such as "functional", "lightweight" and "heavyweight" could not be integrated easily. This solution only shifts the initial problem. To handle this, we propose adding an adaptation layer (Figure 4) between the model used for project management and real project management. This proposal is based on the use of roles and contexts. It aims to make a more flexible allocation of human resources in a project. It aims to substitute the use of the concept of actor by the concept of role, to bring together the various project activities by context and to define an archetype of project. Although this does not solve the whole problem, it should improve the operational implementation of different project configurations. The use of this archetype with a real project is done by using a mapping between roles and actors in the defined contexts. On the one hand, this has the advantage of allowing the definition of projects whose processes are streamlined. And, on other hand, it allows a flexible allocation of human resources. The proposed model takes into account the following entities: Processes, Activities, Phases, Artifacts, flows, resources and relationships, plus the roles and the contexts. The following sections describe some parts of models of the Product / Project Information Repository (PIR) Module of LASCOM since we are not authorized to present the model on the whole.

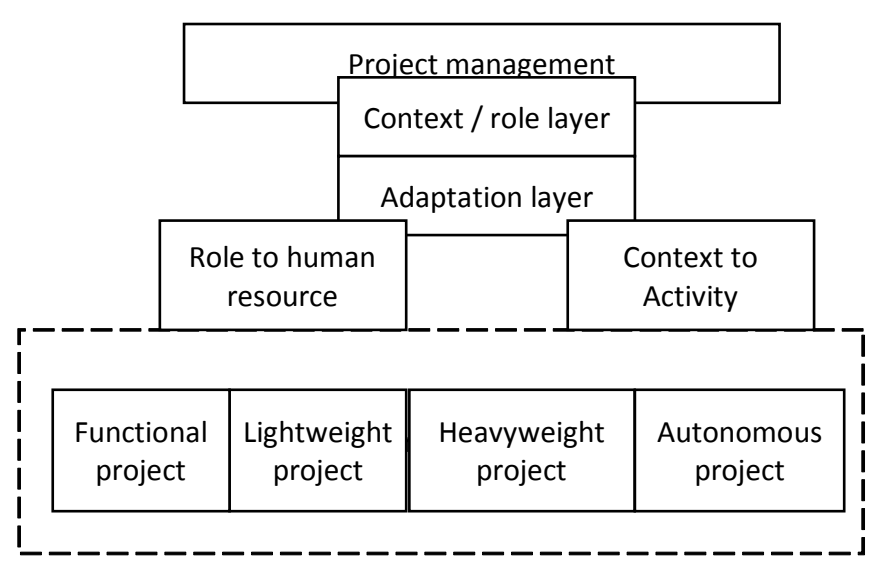

Figure 4. Role and Context Layer

The role concept comes from a sociological theory: the role theory. Since many years, Role concepts have been applied widely in management, sociology and psychology. This concept is very useful in analyzing and modeling the behavior, authority, accountability, tasks, situation and interactions within an organization $[48,49]$.

A role is defined as a cluster of related and goal-directed behaviors characteristic of an individual or group within a specific situation and is considered to be one of the fundamental and defining features of team in particular. Fulfillment and coordination of a set of roles are thought to be necessary so the team can perform effectively and so they can avoid process losses associated with dysfunctional conflict, role ambiguity, and social loafing [49]. Although the concept of role is used for collaborative information systems [48], it has never been implemented as main model for the project management. In this context, we can nevertheless mention the work of Monticolo [50, 51] dealing with KM identification from an organizational approach to model the professional processes implemented in projects via the RIOCK model. But the roles are here considered as generic behaviors. The role model (Figure 5) proposed here is defined by a name, a list of triplets: activation artifacts, activity, targeted artifacts, a list of skills required in a context and a cardinality range. Activation artifacts define the inputs needed for an activity carried out. Targeted artifacts specify the artifacts produced during the activity. The activity itself is performed by one or a set of stakeholders/players. The skills required are related to context and more specifically to the activity to achieve. Finally, the cardinality range defines the number of instances that a role can be played simultaneously in a context. In the real project, the implementation of the activities of a role depends on the presence of a particular context and the presence of activation artifacts. The assignment of one or a set of human resources depends first of its skills, its availability and the cardinality range of the role. This is reflected for example by the fact that the role of project manager in the context of the project requires management skills and can be played by one stakeholder. 


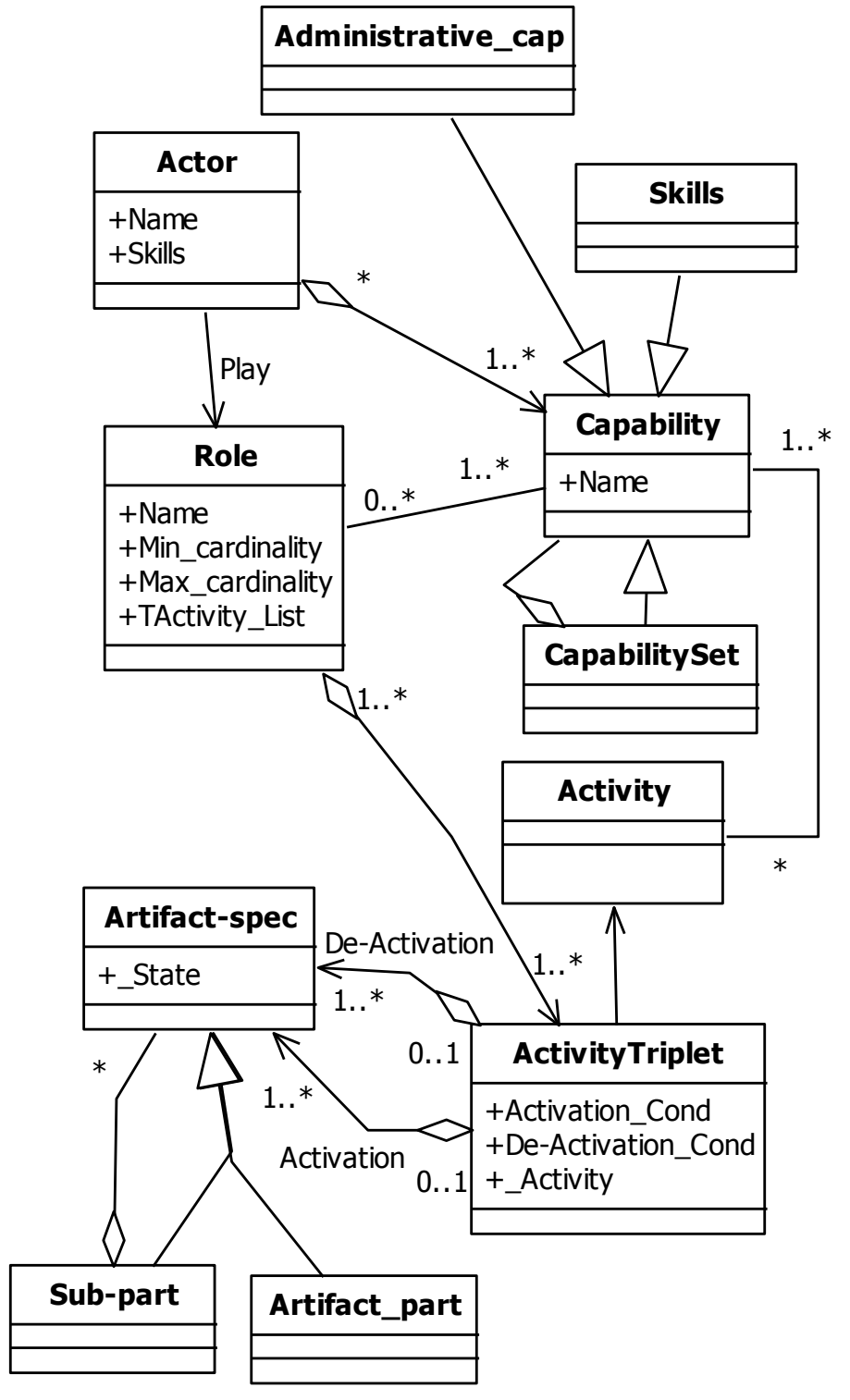

Figure 5. Role mode

To increase the design performance and, consequently, to satisfy customers' requirements and companies' expectations, the decision-maker (usually the project manager) must define an appropriate design context which will facilitate the designers' work. The project manager must be able to set up an efficient, well-knit team based on the design objectives and the designers' needs. Mechanisms that can help the project manager to adapt the design environment to the situation observed must be based on sociologic aspects, management of developments in production systems and information about the product, process and organization. A design environment is defined as the context in which the project manager wants to place the designers in order to achieve the design objectives [16].

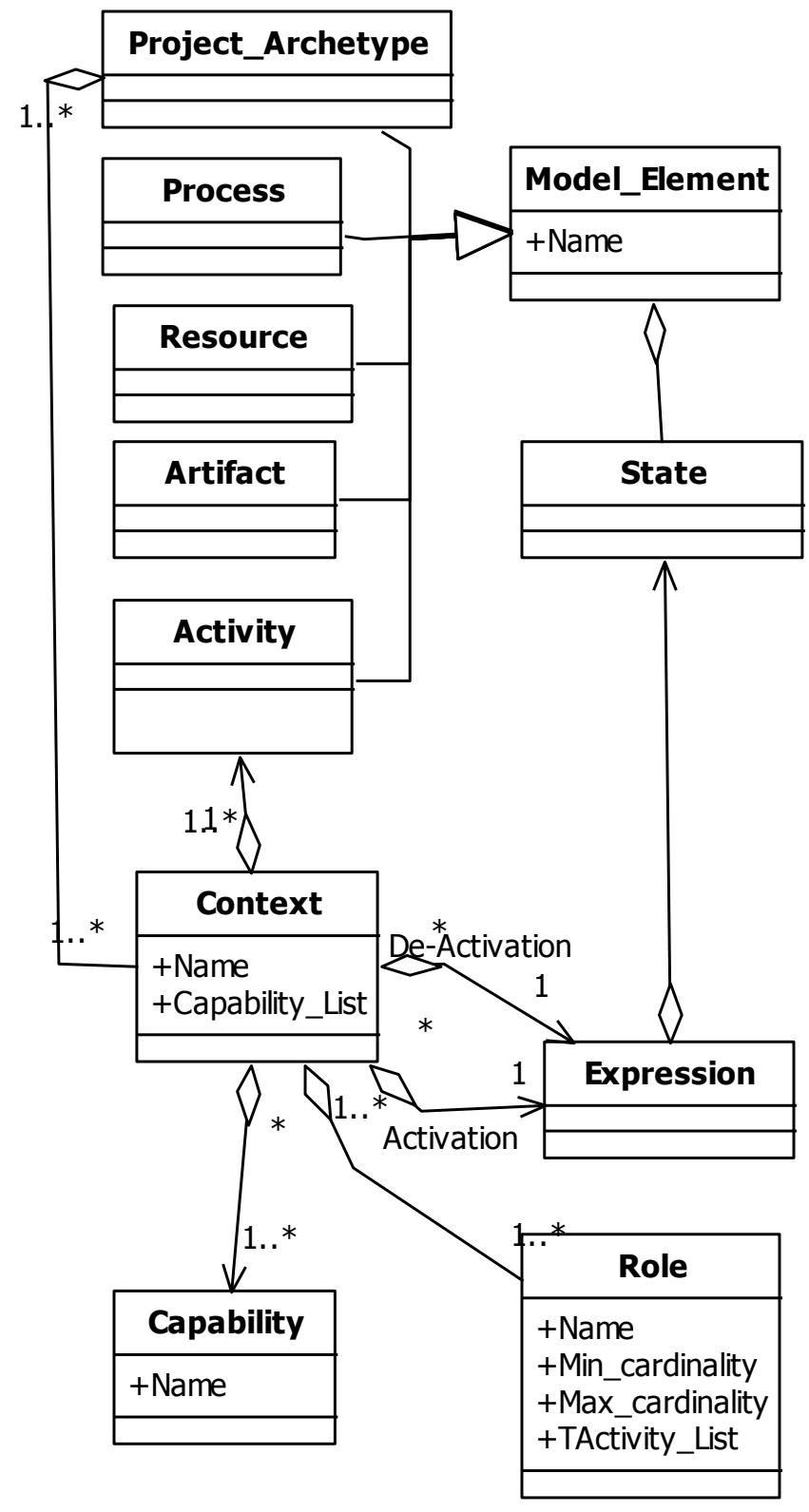

Figure 6. Design environment (context) model

The creation and organization of a design environment require an analysis of the existing design situation. A design situation is defined as the state of the technological system at a given point in time [52] and is characterized as follows:

1. The product, its nature, complexity, status in the process and interfaces has to be taken into account (fig.6, class "artifact").

2. The process, particularly the design approach, the type of design (routine, innovative or creative) and the type of collaboration (fig.6, class "process").

3. The material and financial resources (business premises, computers, budget, etc.) (fig.6, class "resource") 
4. The constraints imposed by the company and the particular constraints of the context (concurrence competition, manufacture or purchase of products, etc.) (in other part of the model, not presented here).

5. The designers, and more particularly, their roles and tasks in the design process. Their experience in relation to similar projects, their knowledge and socialization also have to be taken into account. The aim is to adapt their work environment as closely as possible to their needs (fig.6, classes "capability" and "roles").

To analyze the existing design situation, the aspects defined in the GRAI model had to be taken into account together with the collaboration taxonomy. Based on this description, the design environment (fig.6, class "model element") parameters can then be defined:

- The design framework (design objectives, fields of competence, performance objectives, designers, resources, budget, etc.) (in other part of the model, not presented here).

- The description of the new design context in order to implement:

- The process model of the to-be situation.

- The to-be organization of the design center (from a social viewpoint).

- The to-be activities and the performance levels achieved (fig.6, class "activity”).

- The type of to-be collaboration defined according to the taxonomy proposed [16, 27] (fig.6, class "project archetype").

These parameters define the design environment and can evolve as the project advances. A design environment is distinguished from another by its state (fig. 6, class "state"), and validation requirements related by activation or deactivation of an expression (fig. 6, class “expression") [48].

Properties implemented by the conditions relate to the states of presence or absence of Processes, Activities, Phases, Artifacts and Resources present in a project. A context is defined by a meaningful name, an activation condition, a condition of deactivation and a list of role in collaborative relationship. In the real project, the presence or absence of context is directly related to the conditions of activation and deactivation.

The Mapping between the model-based role and human resources in the real project depends on the nature of the project (Figure 7). In the categories of Wheelwright and Clark [27], four project types are represented with four different configurations. However, it is possible to reduce that number to two, if the view is the structuring of the team. It lefts two configurations: the structures related to the organization and structures associated with the autonomous project. Depending on the characteristics of these settings, two strategies can be used:

- An incremental mapping strategy for project management. The strategy focuses on a selection of human resource skills-based.
- A mapping strategy with planning generation for organizational structure. The strategy focuses on a selection of human resources based on capability. It takes into account the administrative capability and the skills of the human resources.

The Mapping strategies and helps to reconcile the legitimate need of an organization to control the business process while allowing the project to retain its flexibility. On the one hand, the work outlined to define specific contexts with the use of roles. On the other hand, it keeps a lot of freedom on the allocation of roles to project stakeholders.

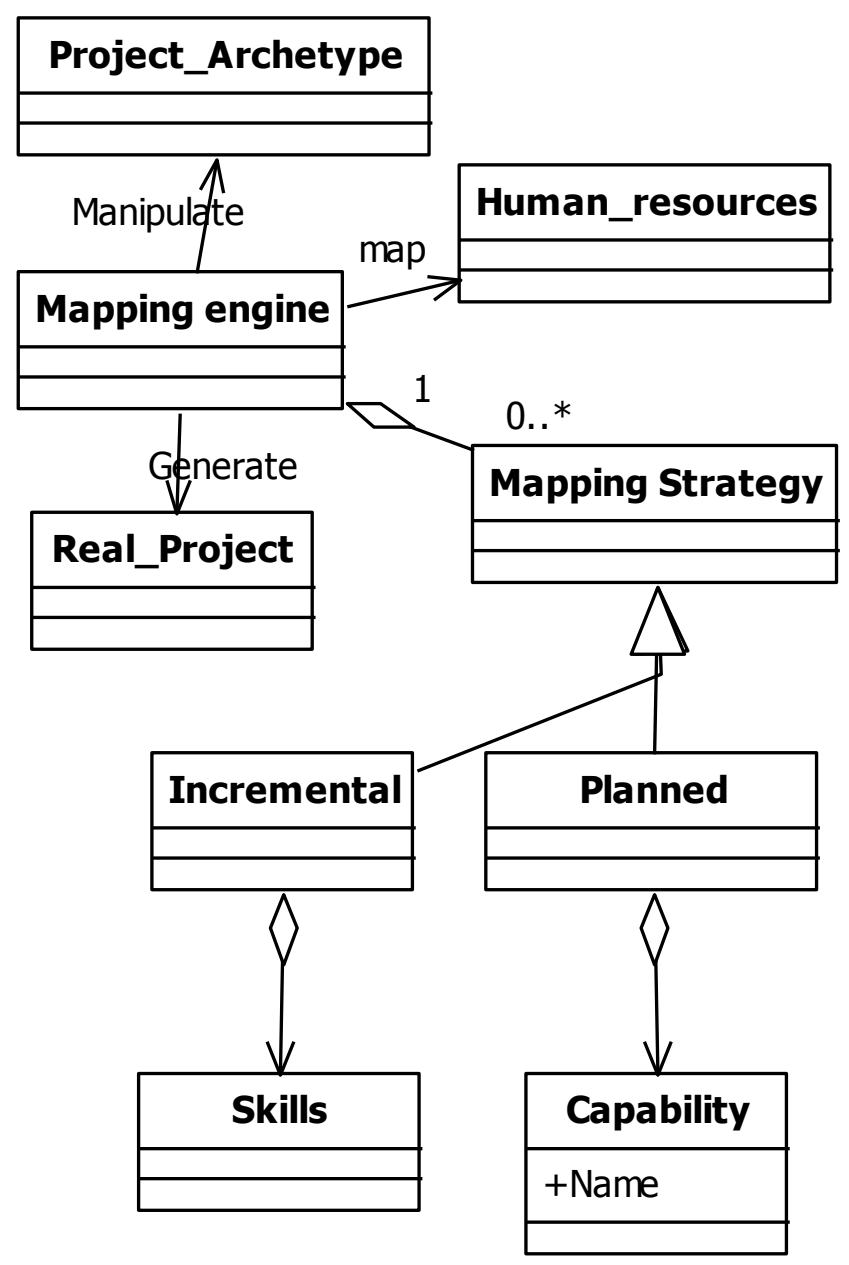

Figure 7. Mapping model

To implement all these models LASCOM decided to interface its PLM solution with SharePoint to be able to benefit from SharePoint portal features: project Share Point site calendar, meetings, ...

Such a solution permits to record the entire change history, comments, suggestions and collaboration points made during the development process and to maintain the complete design intent of the data. It also can be used to trace why certain decisions were made. It organizes data and documents by projects and customers. For every project, users share a 
common collaboration space: users stay focus and they are not diverted by a mass of information which is not relevant to their tasks. It improves collaboration with a dispersed team, permits the project team follow-up and is a powerful decision support. This new solution allows users to:

- Create, Edit Project templates,

- Define data structures (project configurations) for every project,

- Define users, roles and the security model

- Compare actual and template project,

- $\quad$ Subscribe, publish, and distribute data, folders and documents of the project.

This solution improves the efficiency and visibility of key business processes through workflow software and easy-to-use web interfaces. Internal and external stakeholders can more effectively collaborate on key areas such as:

- Project launch

- Graphical layout validation,

- Field/engineering change order,

- Field non conformance

- Work order / Request for quotations,

- Vendor / customer transmittal.

\section{CONCLUSIONS}

The use of projects in firms induces a behavioral change in management practices. This would not be problematic if the models used in organizational management and project management was not so close. The fact that project management software uses these models literally reinforces these changes in practice. As LASCOM uses some of these models in its project management software allows us to observe that implementation of a project is more flexible, whatever its configuration. Moreover, this work also focuses on aspects related to human resources and team in particular. In the PLM solution, we tried to analyze more precisely human behaviors to be more efficient in:

- human-machine interface development,

- the consideration of actors' network during collaborations,

- the consideration of the actors' context of work to be performing.

The PLM solution of LASCOM emphasis the fact that the development of a "human centered" PLM solution is possible and interesting for increase performance of project management. The next major step in this work is to evaluate a generalization of the concepts of roles and contexts to other types of resources and to evaluate the mechanisms necessary for this generalization.

\section{REFERENCES}

[1] O’Donnell, F.J.O., Duffy, A.H.B. (1999). Modelling product development performance. International Conference on Engineering Design, ICED 99, Munich, Germany.
[2] Chen H.H, Kang H.Y., Xing X., Lee A.H.I., Tong Y. (2008). Developing new products with knowledge management methods and process development management in a network. Computers in Industry, Vol.59, pp.242-253.

[3] Girard Ph., Doumeingts G. (2004). Modelling of the engineering design system to improve performance. Computers \& Industrial Engineering, Vol.46, $\mathrm{n}^{\circ} .1, \mathrm{pp} .43-67$.

[4] Robin V., Girard P. (2010). An integrated product-processorganization model to manage design system. International Journal of Product Development, vol. 10, pp. 318-337.

[5] Sudarsan R., Fenves S. J., Sriram R.D., Wang F. (2005). A product information modelling framework for product life cycle management", Computer-Aided Design, Vol. 37, n¹3, pp. 1399-1411.

[6] Lederberg J. (1990). The excitement and fascination of science: reflections by eminent scientists. Vol. 3, Part 1: Annual Reviews, Inc.

[7] Sudarsan R., Subrahmanian E., Bouras A., Fenves S.J., Foufou S., Sriram R.D. (2008). Information sharing and exchange in the context of product lifecycle management: Role of standards. Computer-Aided Design, Vol. 40, Issue 7, pp. 789-800.

[8] Sveiby, K. (1997). The New Organizational Wealth: Managing and Measuring Knowledge Based Assets. San Francisco: Berrett Koehler.

[9] Bean, R.; and Radford, R.W. (2001). The Business Innovation: Managing the Corporate Imagination for Maximum Result. New York, AMACOM.

[10] Bradley P., Jordan P. (1996). “An agreed business model identifying a set of generic business processes". CIMRU, University College Galway, Ireland.

[11] Judson A.S. (1990). "Making strategy happens, transforming plans into reality". Basil Blackwell, London.

[12] Pawar K., Driva H. (1999). "Performance measurement for product design and development in a manufacturing environment". International Journal of Production Economics, Vol. 60-61, pp. 61-68.

[13] Driva H., Pawar K. and Menon U. (1999). "A framework for product development performance metrics", International Journal Business Performance Management, Vol.1/3, pp. 312 326.

[14] Nanni, A.J., Dixon J.R. and Vollman T.E. (1992). "Integrated Performance Measurement: Management Accounting to Support the New Manufacturing Realities". Journal of Management Accounting Research, pp. 1-19.

[15] Girard, P. and G. Doumeingts (2004). "Modelling the engineering design system to improve performance." Computers and Industrial Engineering, Vol. 46, n 1 , pp. 43-67.

[16] Girard, Ph, Robin, V. (2006). "Analysis of collaboration for project design management", Computers in Industry, Vol. 57, Issues 8-9, Pages 817-826.

[17] Robin, V., Rose B., Girard P. (2007). "Modeling collaborative knowledge to support engineering design project manager." Computers in Industry, Vol. 58, n², pp. 188-198.

[18] O’Donnell F., Duffy A., (2005). "Design Performance", Springer ed. 
[19] O’Donnell F.J.O., Duffy A.H.B. (1999). "Modelling product development performance". International Conference on Engineering Design, ICED 99, Munich.

[20] Krishnan, V. and K. Ulrich (2001), "Product Development Decisions: A Review of the Literature", Management Science, Vol. 47, $\mathrm{n}^{\circ} 1, \mathrm{pp} 1-21$.

[21] Project Management Institute (2008), A Guide to the Project Management Body of Knowledge (PMBOK ${ }^{\circledR}$ Guide) Fourth Edition, pmi ed.

[22] Office of Governement Commerce, (2009), Managing Successful Projects with PRINCE 2, 5th edition, The Stationery Office Publisher.

[23] Poulet A., Rose B., Caillaud E. (2011), Ensuring the integration of performance and quality standards in design process management: Codesteer methodology, 18th International Conference on Engineering Design, ICED11, Copenhagen, Denmark.

[24] Corriveau G, Larose V. (2005). "To disguise is it project management best way to be more competitive, more rational and more rapid ?", AIRTO congress, Montpellier, France.

[25] Browning, T.R., (2006), Key concepts in modeling Product Development Processes, Systems Engineering, Vol. 9, Issue 2, pp. $104-128$.

[26] Browning, T.R. (2009), The Many Views of a Process: Towards a Process Architecture Framework for Product Development Processes, Systems Engineering, Vol. 2, Issue 1, pp. 69-90.

[27] Wheelwright, S. C. and Clark, K. B. (1992) Revolutionizing Product Development, Quantum Leaps in Speed, Efficiency, and Quality. The Free Press. New York.

[28] Huth T. (2008). Organizing Cross-Functional New Product Development Projects: The Phase-Specific Effects of Organizational Antecedents, Gabler Edition, ISBN: 3835009265.

[29] Ulrich, K., and Eppinger, S. (2008). Product design and development (4th ed.). Boston, MA: McGraw-Hill/Irwin.

[30] Lillrank P. (2003). The Quality of Standard, Routine and Nonroutine Processes, Organization Studies, Vol. 24, No. 2, pp. 215-233.

[31] Darian W. Unger, Steven D. Eppinger (2009), Comparing Product Development Processes and Managing Risk, International Journal of Product Development, Vol. 8, $\mathrm{n}^{\circ} .4$, pp. 382-402.

[32] Simon H.-A. (1991), Sciences des systèmes, sciences de l'artificiel, p 113-141, Afcet Systèmes, Dunod, Paris.

[33] Howard T.J., Culley S.J., Dekoninck E. (2008). Describing the creative design process by the integration of engineering design and cognitive psychology literature. Design Studies, Vol. $29, \mathrm{n}^{\circ} 2$, pp. $160-180$.

[34] De Meyer A., Loch C. and Pich M. (2002). Managing Project Uncertainty: From Variation to Chaos, Sloan Management Review.

[35] Katzenbach J.R. and Smith D.K. (1993), "The Discipline of Teams," Harvard Business Review.

[36] Paris C.R., Salas E., Cannon-Bowers, J.A., (2000), Teamwork in multi-person systems: a review and analysis,
Taylor and Francis Ltd, Ergonomics, Vol. 43, n ${ }^{\circ}$, issue 1, pp. 1052-1075.

[37] Gottlieb M.R. (2003), Managing group process, Praeger Publishers, ISBN: 1-56720-511-9.

[38] Vertabase, project management software, http://www.vertabase.com/, last accessed Oct. 2011.

[39] Intervals, 2001, project management software, http://www.myintervals.com/tour.php,last accessed Oct. 2011.

[40] Basecamp, project management software, http://basecamphq.com/, last accessed Oct. 2011.

[41] Chatfield C., Johnson T. (2010). Microsoft Project 2010 Step by Step, Microsoft Press, ISBN: 0735626952.

[42] Klambauer T. (2008). "Comparison of Project management Software", Johannes Kepler University Linz seminar, Version 1.3 .

[43] Heldman, K.. (2009). PMP Project Management Professional Exam study Guide, 5th edition, SYBEX.

[44] Raymond L., Bergeron F., (2008), Project management information systems, An empirical study of their impact on project managers and project success, International Journal of Project Management, Vol. 26, Issue 2, pp. 213-220.

[45] White D.; Fortune J., (2002), Current practice in project management - an empirical study, International Journal of Project Management, Vol. 20, $\mathrm{n}^{\circ}$, pp. 1-11.

[46] Araujo C., Amaral D., Capaldo A. (2008). Comparative Analysis of Project Management Information Systems to Support Concurrent Engineering,, Advanced Concurrent Engineering, Collaborative Product and Service Life Cycle Management for a Sustainable World,PB - Springer London,SP- pp. 341-348.

[47] Boucher X., Bonjour E., Grabot B. (2007), Formalisation and use of competencies for industrial performance optimisation: A survey, Computers in Industry, Vol. 58, Issue 2, pp 98-117.

[48] Zhu, H., Roles in information systems: A survey, IEEE transaction on systems,man, and cybernetics, vol 38,N. 32008

[49] Sluss D.M. (2010). Role Theory in organizations: a relational perspective, Handbook of I/O-Psycology, Washigton.

[50] Monticolo D., Gomes S., Hilaire V., Serrafero P. (2007); 'Knowledge capitalization process linked to the design process', International Join Conference on Artificial Intelligence (IJCAI). Workshop on Knowledge Management and Organisational Memories, Hyderabad-India.

[51] Monticolo D., Gomes S., Hilaire V. and Koukam A. (2008), "An approach to Support the Knowledge Management Process inside Professional Activities", in International Journal of Product Lifecycle Management.

[52] Eder W.E. A typology of designs and designing (2003). International Conference on Engineering Design, ICED 03, Stockholm. 